Submission ID: 43782

\title{
Geochemical Characteristics of Source Rocks of the Southern Part of the
}

\section{Preurals Foredeep}

A.V. Osipov* (Gubkin Russian State University of Oil and Gas), M.V. Zaharchenko (Gubkin Russian State University of Oil and Gas), M.M. Lyushin (Gubkin Russian State University of Oil and Gas), A.S. Nefedova (Gubkin Russian State University of Oil and Gas), L.I. Kerimova (Gubkin Russian State University of Oil and Gas)

\section{SUMMARY}

The article presents the results of the interpretation of a complex geochemical study of the organic matter of samples of different age of Paleozoic rocks from wells in the southern part of the PreUrals foredeep. It was found that in all the studied oil and gas complexes (Lower Devonian - Frasnian, Frasnian - Tournaisian, Visean - Bashkir and Lower Permian) have their own syngenetic source rocks characterized by different generational potential and confinement to a particular litho-facies zones. 
А.В. Осипов* (РГУ нефти и газа (НИУ) имени И.М. Губкина), М.В. Захарченко (РГУ нефти и газа (НИУ) имени И.М. Губкина), М.М. Люшин (РГУ нефти и газа (НИУ) имени И.М. Губкина), А.С. Нефедова (РГУ нефти и газа (НИУ) имени И.М. Губкина), Л.И. Керимова (РГУ нефти и газа (НИУ) имени И.М. Губкина)

В пределах южной части Предуральского прогиба установлены нижнедевонско-франский, франско-турнейский, визейско-башкирский и нижнепермский нефтегазоносные комплексы (НГК). Все НГК палеозоя располагают собственными сингенетичными нефтегазоматеринскими толщами (НГМТ), характеризующимися разным генерационным потенциалом и приуроченностью к определенным лито-фациальным зонам. Наличие син-, эпии параавтохтонных битумоидов в НГК палеозоя, свидетельствует о развитии в этих комплексах наряду с процессами генерации углеводородов (УВ) и аккумуляции УВ за счет их эмиграции из нижележащих материнских толщ. Геохимические исследования органического вещества (ОВ) образцов горных пород из пробуренных за последнее десятилетие скважин, позволяют выделить материнские толщи с различным генерационным потенциалом (Рисунки 1, 2). Нижнепермский и визейско-башкирский комплексы содержат материнские породы, качество которых изменяется от очень плохого до хорошего. Кероген НГМТ данных комплексов I и II типа, генерирующий преимущественно нефть. Франско-турнейский и нижнедевонскофранский комплексы содержат материнские породы от очень плохого до удовлетворительного качества. Для всех исследуемых комплексов характерным является проявление повышенных значений кислородного индекса, свидетельствующих об окислительных процессах. По показателю водородного индекса материнские породы нижнепермского и визейскобашкирского комплексов демонстрируют диапазон эволюционного поля от нескольких мг УВ / г Сорг до 500-600 мг УВ /г Сорг, керогеном этих НГМТ преимущественно II-III типа, ответственного за генерацию нефти и газа. Органическое вещество материнских пород комплексов - зрелое. По этому параметру (НI) ОВ образцов пород франско-турнейского и нижнедевонско-франского возрастов отвечает качеству материнской породы удовлетворительного качества. Породы содержат кероген III и IV типов, способных генерировать только газ. Попадание в область «нефтяного окна» и по значению параметра индекса продуктивности в интервале 0,2-0,4 наиболее четко проявляется на образцах материнских пород нижнепермского возраста. Часть образцов находятся в зоне незрелых или близко к этому интервалу. Характерным является также присутствие нефтенасыщенных образцов, указывающих на эффект наложения нефти стороннего источника, преобладание ОВ пород, находящегося по параметру $\mathrm{T} \max \left(440-460{ }^{\circ} \mathrm{C}\right)$ в условиях формирования нефти и минимальное количество образцов с перезрелым ОВ. Для нефтегазоматеринских пород визейско-башкирского, франско-турнейского и нижнедевонско-франского комплексов характерно преобладание перезрелых ОВ, ответственных за генерацию газа, редкое попадание в «нефтяное окно» и присутствие незрелых образцов. Только образцы пород нижнепермского возраста демонстрируют, в основном, значения полного генерационного потенциала от высокого до превосходного, с минимальным присутствием в зоне удовлетворительных материнских пород. Значения по нефтегазоматеринским породам других нефтегазоносных комплексов перекрывают весь диапазон значений этого параметра от удовлетворительного до превосходного.

Таким образом в результате проведенных исследований в пределах Предуральского прогиба выделяются следующие НГМТ - силурийская и нижнедевонская, среднедевонсконижнефранская, франско-фаменская, верхнедевонские-турнейская, визейская окскобашкирская, средне-верхнекаменноугольная и нижнепермская. В пределах южной части Предуральского прогиба хорошим нефтегазоматеринским потенциалом обладают отложения возраста $\mathrm{C} 2 \mathrm{~m}-\mathrm{C} 3+\mathrm{P} 1 \mathrm{a}$, представленные чередованием аргиллитов и доломитов глинистых (тип керогена - II и II / III), и сакмаро-артинские отложения нижней перми, представленные 


\title{
EAGE
}

мергелями известково-доломитовыми с прослоями известняков (тип керогена - II / III). В разрезе отложений нижней перми - среднего карбона выделены две высокопродуктивные нефтематеринские толщи. Одна из них, относительно менее продуктивная (вероятно, из-за окисленности ОВ в диагенезе), связана с сакмаро-артинскими отложениями нижней перми; другая - c ассельско-верхне-среднекаменноугольными. Степень катагенетической преобразованности органического вещества изученных пород свидетельствует о том, что исследованные отложения уже вступили в главную зону нефтеобразования. Также, возможно, материнские отложения, находящиеся на стадии поздней зрелости, выделены в отложениях башкирского яруса среднекаменноугольной системы. Однако ввиду высокой степени катагенного преобразования органического вещества изученных пород оценить характеристики материнских толщ затруднительно.
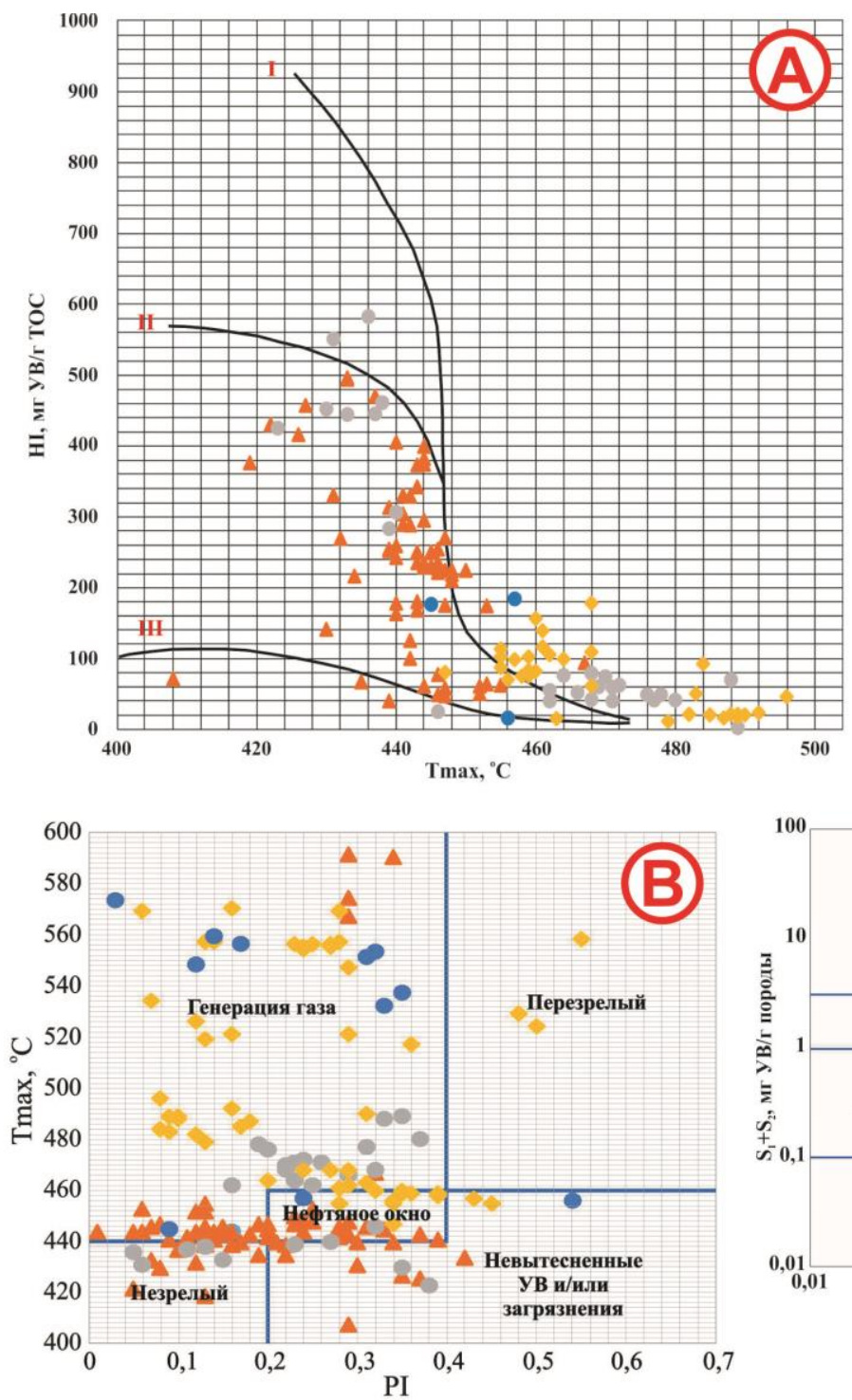

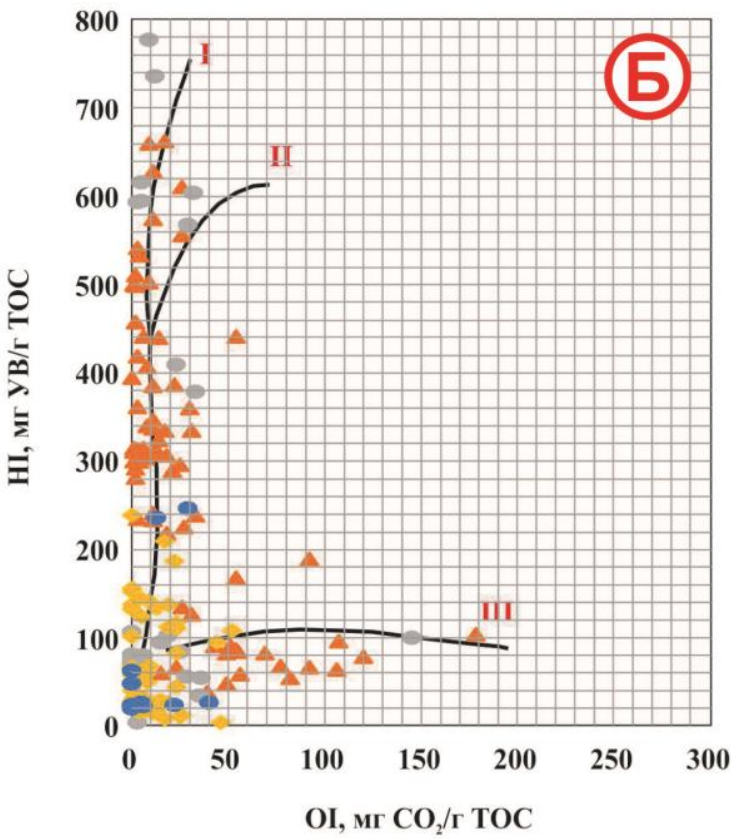

OI, $\mathrm{M \Gamma} \mathrm{CO}_{2} / \mathrm{r}$ TOC

\section{Нефтегазоносные комплексы:}

\author{
$\Delta$ Нижнепермский Визейско-Башкирский \\ Франско-Турнейский Нижнедевонско-Франский
}

Рисунок 1 Диаграммы зависимостей: A - Ван-Кревелена (водородного индекса (HI) от максимальной температуры пиролиза $\left(T_{\max }\right)$ ); Б - Ван-Кревелена (водородного индекса (HI) от кислородного индекса (OI)); В - максимальной температуры пиролиза (T $\left.T_{\max }\right)$ от индекса продуктивности (PI); $\Gamma$ - полного генерационного потенциала $\left(S_{1}+S_{2}\right)$ от общего органического углерода (ТОС) 
EAGE

EUROPEAN

ASSOCIATION OF

ENGINEERS

a

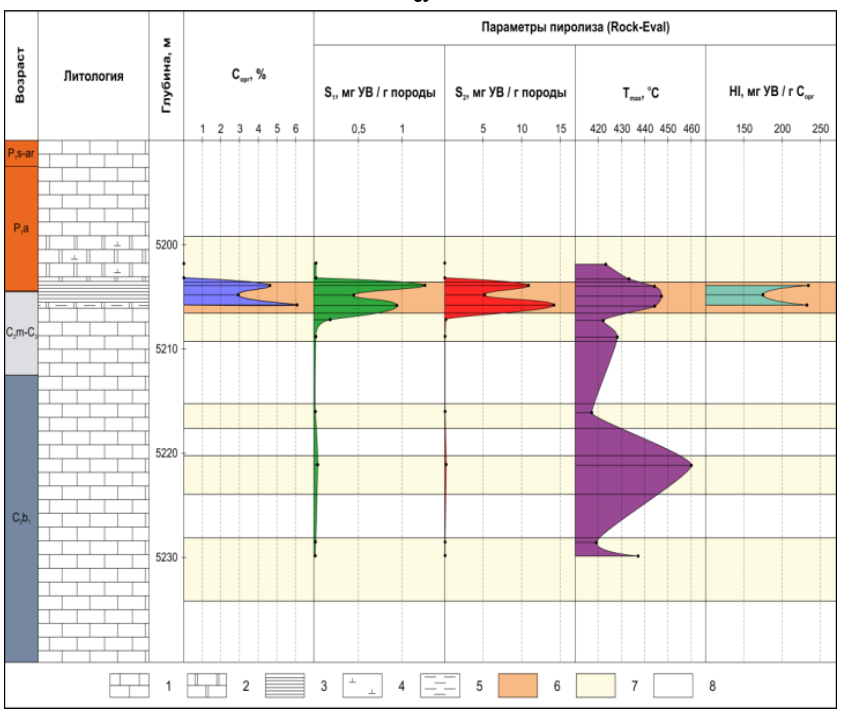

B

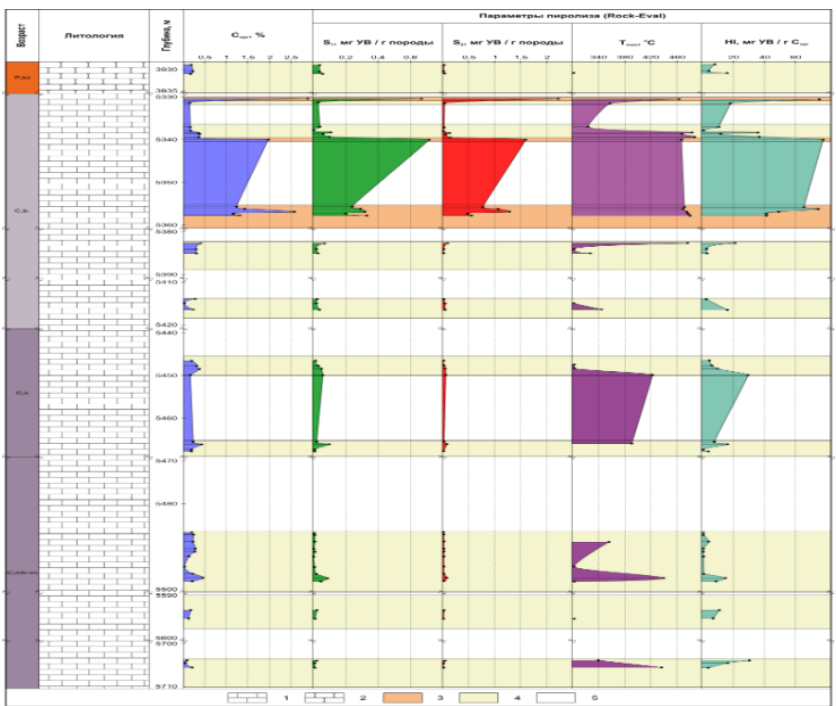

д

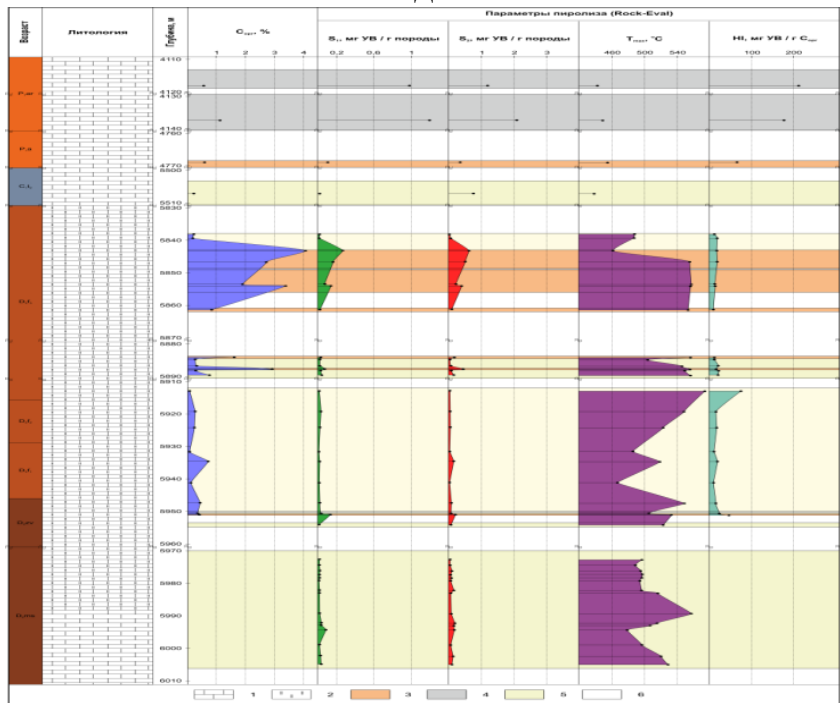

6
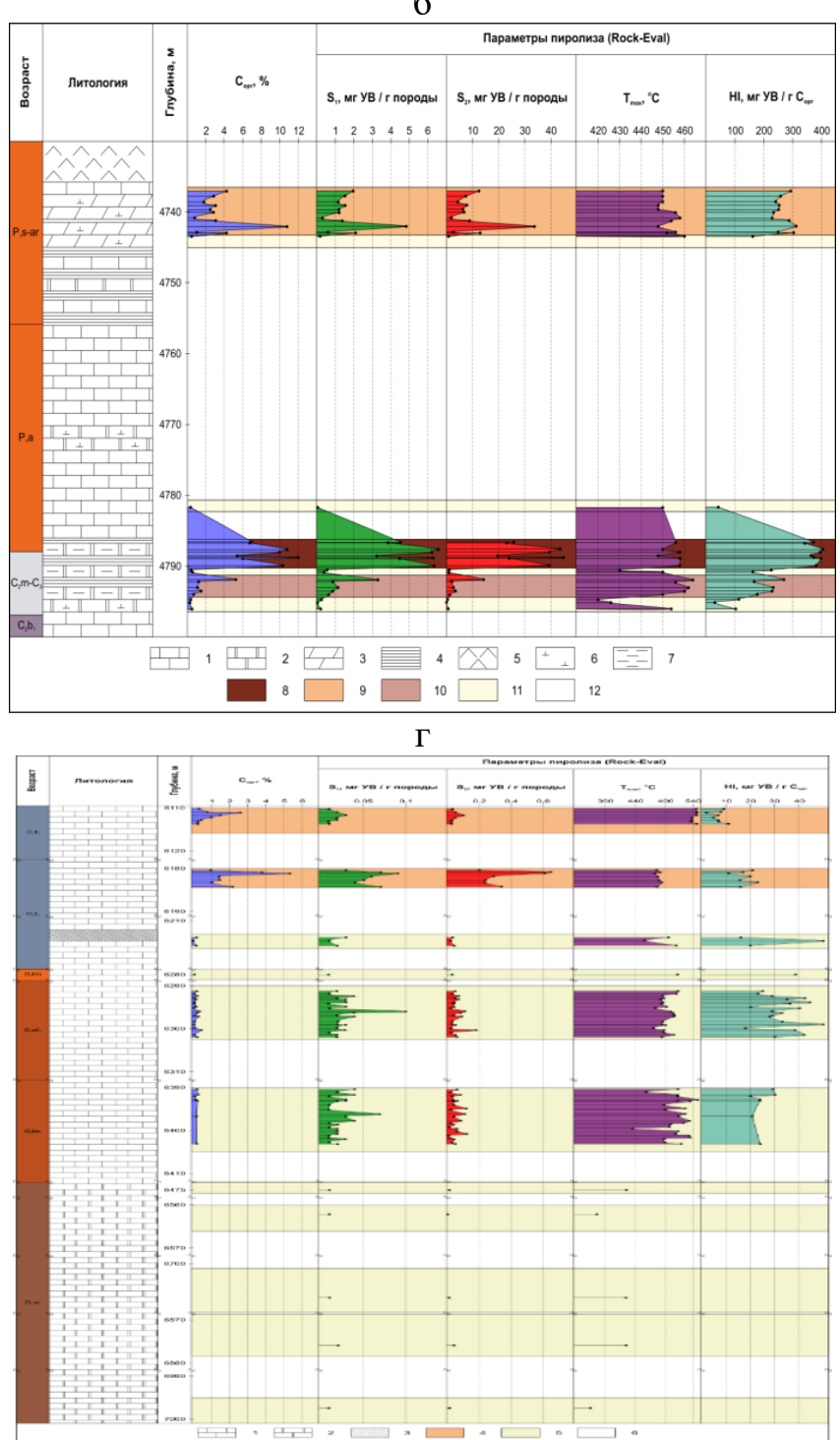

e



Рисунок 2 Фрагменты геохимических разрезов скважин: а - Акобинская 172; б - Кзылобинская 162; в - Корниловская 150; - Верииновская 501; д - Нагумановская 1; е - Чиликсайская 35 


\section{Благодарность}

Исследования проведены при финансовой поддержке Минобрнауки России в рамках Задания № 5.2907.2017/ПЧ на выполнение научно-исследовательской работы по проектной части государственного задания в сфере научной деятельности.

\section{Библиография}

1. Guliev I.S., Kerimov V.Yu., Mustaev R.N. Fundamental challenges of the location of oil and gas in the South Caspian Basin // Doklady Earth Sciences. - Moscow, 2016. - V. 471, №1. - PP. 1109-1112. 2. Kerimov V.Yu., Serikova U.S., Mustayev R.N., Guliyev I.S. Deep oil-and-gas content of South Caspian Basin // Neftyanoe khozyaystvo - Oil Industry. - Moscow, 2014. - №5. - PP. 39-42

3. Kerimov V.Yu., Mustaev R.N., Senin B.V., Lavrenova E.A. Basin modeling tasks at different stages of geological exploration // Neftyanoe khozyaystvo - Oil Industry. - Moscow, 2015. - №4. PP. 26-29.

4. Kerimov V.Yu., Mustaev R.N., Dmitrievsky S.S., Yandarbiev N.Sh., Kozlova E.V. The shale hydrocarbons prospects in the low permeability khadum formation of the Pre-Caucasus // Neftyanoe Khozyaystvo - Oil Industry. - Moscow, 2015. - №10. - PP. 50-53.

5. Kerimov V.Y., Gorbunov A.A., Lavrenova E.A., Osipov A.V. Models of hydrocarbon systems in the Russian Platform-Ural junction zone // Lithology and Mineral Resources. - Moscow, 2015. - V. 50, №5. - PP. 394-406.

6. Kerimov V.Yu., Shilov G.Ya., Mustayev R.N., Dmitrievskiy S.S. Thermobaric conditions of hydrocarbons accumulations formation in the low-permeability oil reservoirs of khadum suite of the Pre-Caucasus // Neftyanoe Khozyaystvo - Oil Industry. - Moscow, 2016. - №2. - PP. 8-11.

7. Kerimov V.Yu., Osipov A.V., Lavrenova E.A. The hydrocarbon potential of deep horizons in the south-eastern part of the Volga-Urals oil and gas province // Neftyanoe khozyaystvo - Oil Industry. Moscow, 2014. - №4. - PP. 33-35.

8. Kerimov V.Yu., Lavrenova E.A., Kruglyakova M.V., Gorbunov A.A. Oil and gas prospects of crimea and west part of Azov sea // Neftyanoe khozyaystvo - Oil Industry. - Moscow, 2014. - №9. PP. 66-70.

9. Kerimov V.Y., Rachinsky M.Z. Geofluid dynamic concept of hydrocarbon accumulation in natural reservoirs // Doklady Earth Sciences. - Moscow, 2016. - Vol. 471, №1. - PP. 1123-1125.

10. Kerimov V.Yu., Mustaev R.N., Bondarev A.V. Evaluation of the organic carbon content in the low-permeability shale formations (as in the case of the Khadum suite in the Ciscaucasia region // Oriental Journal of Chemistry. - India, 2016. - Vol. 32, №6. - PP. 1-7.

11. Kerimov V.Yu., Mustaev R.N., Serikova U.S., Lavrenova, E.A., Kruglyakova M.V. Hydrocarbon generation-accumulative system on the territory of Crimea Peninsula and adjacent Azov and Black Seas Neftyanoe khozyaystvo // Oil Industry. - Moscow, 2015. - №2.

12. Peters K.E., Cassa M.R. «Applied source rock geochemistry», The petroleum system - from source to trap, AAPG Memoir 60, 1994, p. 93-120;

13. Дахнова М.В. «Применение геохимических методов исследований при поисках, разведке и разработке месторождений углеводородов», Геология нефти и газа, 2007, №2;

14. Осипов А.В. «Геохимические предпосылки нефтегазоносности Бельской впадины и прилегающих территорий», Нефть, газ и бизнес, 2012, №11, с. 44-49;

15. Чахмахчев В.А. «Геохимические исследования и методы при поисках и разведке нефти и газа: Учебное пособие», Москва: ГУП Издательство «Нефть и газ», 2002, с. 115.

\section{References}

1. Guliev I.S., Kerimov V.Yu., Mustaev R.N. Fundamental challenges of the location of oil and gas in the South Caspian Basin // Doklady Earth Sciences. - Moscow, 2016. - V. 471, №1. - PP. 1109-1112. 2. Kerimov V.Yu., Serikova U.S., Mustayev R.N., Guliyev I.S. Deep oil-and-gas content of South Caspian Basin // Neftyanoe khozyaystvo - Oil Industry. - Moscow, 2014. - №5. - PP. 39-42 
3. Kerimov V.Yu., Mustaev R.N., Senin B.V., Lavrenova E.A. Basin modeling tasks at different stages of geological exploration // Neftyanoe khozyaystvo - Oil Industry. - Moscow, 2015. - №4. PP. 26-29.

4. Kerimov V.Yu., Mustaev R.N., Dmitrievsky S.S., Yandarbiev N.Sh., Kozlova E.V. The shale hydrocarbons prospects in the low permeability khadum formation of the Pre-Caucasus // Neftyanoe Khozyaystvo - Oil Industry. - Moscow, 2015. - №10. - PP. 50-53.

5. Kerimov V.Y., Gorbunov A.A., Lavrenova E.A., Osipov A.V. Models of hydrocarbon systems in the Russian Platform-Ural junction zone // Lithology and Mineral Resources. - Moscow, 2015. - V. 50, №5. - PP. 394-406.

6. Kerimov V.Yu., Shilov G.Ya., Mustayev R.N., Dmitrievskiy S.S. Thermobaric conditions of hydrocarbons accumulations formation in the low-permeability oil reservoirs of khadum suite of the Pre-Caucasus // Neftyanoe Khozyaystvo - Oil Industry. - Moscow, 2016. - №2. - PP. 8-11.

7. Kerimov V.Yu., Osipov A.V., Lavrenova E.A. The hydrocarbon potential of deep horizons in the south-eastern part of the Volga-Urals oil and gas province // Neftyanoe khozyaystvo - Oil Industry. Moscow, 2014. - №4. - PP. 33-35.

8. Kerimov V.Yu., Lavrenova E.A., Kruglyakova M.V., Gorbunov A.A. Oil and gas prospects of crimea and west part of Azov sea // Neftyanoe khozyaystvo - Oil Industry. - Moscow, 2014. - №9. PP. 66-70.

9. Kerimov V.Y., Rachinsky M.Z. Geofluid dynamic concept of hydrocarbon accumulation in natural reservoirs // Doklady Earth Sciences. - Moscow, 2016. - Vol. 471, №1. - PP. 1123-1125.

10. Kerimov V.Yu., Mustaev R.N., Bondarev A.V. Evaluation of the organic carbon content in the low-permeability shale formations (as in the case of the Khadum suite in the Ciscaucasia region // Oriental Journal of Chemistry. - India, 2016. - Vol. 32, №6. - PP. 1-7.

11. Kerimov V.Yu., Mustaev R.N., Serikova U.S., Lavrenova, E.A., Kruglyakova M.V. Hydrocarbon generation-accumulative system on the territory of Crimea Peninsula and adjacent Azov and Black Seas Neftyanoe khozyaystvo // Oil Industry. - Moscow, 2015. - №2.

12. Peters K.E., Cassa M.R. «Applied source rock geochemistry», The petroleum system - from source to trap, AAPG Memoir 60, 1994, p. 93-120;

13. Dakhnova M.V. «Primenenie geokhimicheskikh metodov issledovaniy pri poiskakh, razvedke i razrabotke mestorozhdeniy uglevodorodov», Geologiya nefti i gaza, 2007, №2;

14. Osipov A.V. «Geokhimicheskie predposylki neftegazonosnosti Bel'skoy vpadiny i prilegayushchikh territoriy», Neft', gaz i biznes, 2012, №11, p. 44-49;

15. Chakhmakhchev V.A. "Geokhimicheskie issledovaniya i metody pri poiskakh i razvedke nefti i gaza: Uchebnoe posobie», Moskva: GUP Izdatel'stvo «Neft' i gaz», 2002, p. 115. 